comme celle de la kinase JNK, aboutissant à l'activation du complexe AP1 [14]. L'utilisation de modèles expérimentaux et le développement de différentes lignées de nature $\mathrm{B}$ ou $\mathrm{T}$ permettront de mieux circonscrire les différents mécanismes d'activation cellulaire et de transformation maligne liés à l'EBV [3].

Ce sont ces différentes approches simultanées (la meilleure détection de l'EBV dans les tumeurs, la caractérisation de plus en plus précise du comportement de l'EBV dans les cellules infectées tumorales ou non tumorales et le développement de modèles in vitro) qui permettront d'avoir une attitude préventive des proliférations tumorales associées à l'EBV par une intervention directe sur ce virus, la vaccination par exemple [15]

\section{RÉFÉRENCES}

1. Masucci MG, Levistsky V, Frisan T, Levistkaya J, De Campos-Lima PO. Virus induced cancer : the lesson of Epstein-Barr virus. In Touraine JL, et al., eds. Cancer in transplantation, prevention and treatment. Amsterdam : Kluwer Academic Publishers, 1996 : 161-75.

2. Marelle L, Rea D, Raphael M. Le virus d'Epstein-Barr et les proliférations lymphoides. Med Sci 1993 ; 9 : 693-700.
3. Weiss LM, Chang KL. Association of the Epstein-Barr with hematolymphoid neoplasia. Adv Anat Pathol 1996 ; 3 : 1-15.

4. Robertson K, Ambinder RF. Methylation of the Epstein-Barr virus genome in normal lymphocytes. Blood 1997 ; 90 : 4480-4.

5. Herbst H, Foss HD, Samol J, Araujo I, Klotzbach H, Krause H, Agathanggelou A, Niedobitek G, Stein H. Frequent expression of interleukin-10 by Epstein-Barr virus-harboring tumor cells of Hodgkin's disease. Blood 1996 ; 87 : 2918-29.

6. Bhatia K, Raj A, Guitierrez MI, Judde JG, Spangler G, Venkatesh H, Magrath IT. Variation in the sequence of Epstein-Barr virus nuclear antigen 1 in normal peripheral blood lymphocytes and in Burkitt's lymphomas. Oncogene 1996 ; 13 : 177-81.

7. Jox A, Rohen C, Belge G, Belge G, Bartnitzke S, Pawlita M, Diehl V, Bullerdiek J, Wolf J. Integration of Epstein-Barr virus in Burkitt's lymphomas cells leads to a region of enhanced chromosome instability. Ann Oncol 1997; 8 : 5131-5.

8. Heslop HE, Rooney CM. Adoptive cellular immunotherapy for EBV lymphoproliferative disease. Immunol Rev 1997 ; 157 : 217-22.

9. Ometto L, Menin C, Masiero S, Bonaldi L, Del Mistro A, Cattelan AM, D'Andrea E, De Rossi A, Chieco-Bianchi L. Molecular profile of Epstein-Barr virus in immunodeficiency virus type1-related lymphadénopathies and lymphomas. Blood 1997; 90 : 313-22.

10. Berger C, McQuain C, Sullivan JL, Nadal D, Quesenberry Pf, Knecht H. The 30-bp deletion variant of Epstein-Barr virus encoded latent membrane protein-1 prevails in acute infectious mononucleosis. J Infect Dis 1997 ; $176: 1370-3$.

11. Horenstein MG, Nador RG, Chadburn A, Hyjek EM, Inghirami G, Knowles D, Cesarman E. Epstein-Barr virus latent gene expression in primary effusion lymphomas containing kaposi's sarcoma-associated herpes virus/human herpes virus-8. Blood 1997 ; 90 : 1186-91.

12. Farrell PJ. Epstein-Barr virus immortalizing genes. Trends Microbiol 1995 ; 3 : 105-9.

13. Mosialos G, Birkenbach M, Yalamanchili R, Vann Abdale T, Ware C, Kieff E. The Epstein-Barr virus transforming LMP1 engages signaling proteins for the tumor necrosis factor receptor family. Cell $1995 ; 80: 389-99$.

14. Kieser A, Kilger E, Gires O, Ueffing M, Kolch W, Hammerschmidt W. Epstein-Barr virus latent membrane protein-1 triggers AP1 activity via the c-Jun-terminal kinase cascade. $E M B O J 1997 ; 16: 6478-85$.

15. Moss DJ, Schmidt C, Elliot S, Suhrbier A, Burrows S, Khanna R. Strategies involved in developping an effective vaccine for EBV-associated disease. Adv Cancer Res 1996; 50 : $213-45$.

\section{TIRÉS À PART}

M. Raphaël.

\title{
Défaite du référendum scientophobe en Suisse
}

Les promoteurs du référendum d'initiative populaire visant à interdire, en Suisse, l'utilisation du génie génétique - que nous avions, dans ces colonnes, dénoncé comme «scientophobe" $\left(\mathrm{m} / \mathrm{s} 1998, n^{\circ} 1, p .3\right)$ - en ont finalement été pour leurs frais. N'ayant pas réussi à intéresser vraiment les électeurs (dont seuls $40 \%$ se sont exprimés), ils n'ont pas non plus réussi à convaincre puisque à peine $33 \%$ des votants les ont rejoints, ce qui veut dire que $13 \%$ seulement de la population a finalement adhéré à leur texte. En bref, la montagne suisse a accouché d'une souris... transgénique!

Cette défaite est d'abord un soulagement pour les scientifiques, en Suisse mais aussi dans toute notre communauté internationale, car les conséquences d'un vote contraire auraient été dramatiques, interdisant à nos collègues helvétiques la poursuite de leurs travaux et jetant la suspicion, par-delà toutes les frontières, sur la recherche biologique. Elle est ensuite une victoire, qu'il nous paraît légitime de célébrer, des scientifiques suisses et de tous ceux qui se sont mobilisés autour d'eux depuis des mois. Face à une initiative qui mettait en cause directement l'avancée scientifique en attaquant les développements technologiques qui la permettent, les scientifiques ont réussi à faire valoir la différence essentielle qui existe entre l'acquisition des connaissances, qui requiert une liberté fondamentale dans les laboratoires, et les problèmes techniques et philosophiques que soulève, légitimement, l'utilisation de ces connaissances hors du cadre de la science.

En repoussant l'interdiction de la technologie du gène, les électeurs suisses ont montré qu'ils faisaient la part des choses, mais cette épreuve doit sans doute servir de coup de semonce à l'ensemble de la communauté scientifique. En rappelant, tout d'abord, que si notre rôle dans la société est d'abord d'acquérir des connaissances, nous ne pouvons le faire valablement qu'environnés de la confiance de la population, ce qui réclame de notre part un effort de transmission de ces connaissances, volontariste mais dépourvu de tout sensationnalisme. En précisant ensuite, comme l'ont fait les scientifiques suisses, que la création de connaissances qui est notre tâche est avant tout une activité culturelle, au bénéfice commun de l'humanité. On ne peut, ni ne doit, appliquer à cette activité les règles et les bornes qui s'imposent à l'évidence lorsqu'il s'agit de transférer des connaissances nouvelles, biologiques ou non, dans le cadre socio-économique. En parcicipant, enfin, aux débats de société que doit susciter - et qui doivent précéder - chacun de ces transferts.

Marc Peschanski Rédacteur en chef 